\title{
Pyrosequencing Assessment of Soil Microbial Communities in Organic and Conventional Potato Farms
}

\author{
Akifumi Sugiyama and Jorge M. Vivanco, Center for Rhizosphere Biology, Department of Horticulture and Land- \\ scape Architecture, Colorado State University, Fort Collins 80523; Sastry S. Jayanty, San Luis Valley Research \\ Center, Department of Horticulture and Landscape Architecture, Colorado State University, Center 81125; and \\ Daniel K. Manter, United States Department of Agriculture-Agricultural Research Service, Soil-Plant-Nutrient Re- \\ search Unit, Fort Collins, CO 80526
}

\begin{abstract}
Sugiyama, A., Vivanco, J. M., Jayanty, S. S., and Manter, D. K. 2010. Pyrosequencing assessment of soil microbial communities in organic and conventional potato farms. Plant Dis. 94:1329-1335.

Organic farming is frequently touted as being beneficial to soil health by increasing microbial community diversity; however, contradictory results exist in the literature. In this study, we compared several organic and conventional potato farms in Colorado for differences in soil nutrients and microbial communities using 454 pyrosequencing of the 18S ribosomal RNA gene. Organic farms showed a slightly higher diversity and evenness within the microbial community compared with conventional farms. No difference in the number of observed or estimated total operational taxonomic units (OTUs) was observed between management strategies. However, the relative abundance of 16 OTUs (3\% genetic distance) differed between the organic and conventional farms, with seven increasing and nine decreasing in organic farms. A variety of known potato fungal pathogens (e.g., Alternaria spp., Ulocladium spp., and Pythium ultimum) were detected in the soil, including three different OTUs (3\% genetic distance) with a high homology to the early blight pathogen Alternaria solani. Relative abundance for Alternaria spp. was higher in conventional farms (relative abundance 30.15 versus $7.8 \%$ ), whereas the relative abundance for P. ultimum was higher in organic farms (relative abundance 0.25 versus $0.05 \%$ ). Quantitative polymerase chain reaction, using primers specific for A. solani, Phoma foveata, and Pythium ultimum, yielded similar results to the pyrosequencing, validating the use of pyrosequencing data for the quantification of OTU relative abundances.
\end{abstract}

Conventional farming, using chemical fertilizers and pesticides, has increased crop yields but posed severe environmental problems such as soil degradation, increased use of fossil fuels, water pollution, and the development of species that show pesticide resistance $(14,25)$. Organic farming is an alternative to conventional farming that has the possibility of reducing the negative effects of conventional agriculture. In 2007, 32.3 million ha of agricultural lands were maintained organically worldwide, and this trend seems to be increasing (12). A long-term study conducted in Europe showed that, under organic farming, crop yields may be reduced by $20 \%$ but reduced fertilizer and pesticide applications and energy costs can offset these losses (20). Although organic farm-

Corresponding author: D. K. Manter

E-mail: daniel.manter@ars.usda.gov

Accepted for publication 6 July 2010 .

doi:10.1094/PDIS-02-10-0090

This article is in the public domain and not copyrightable. It may be freely reprinted with customary crediting of the source. The American Phytopathological Society, 2010. ing is thought to be benign on the environment, the impact of organic farming on the surrounding environment such as the overall soil microbiota remains to be assessed sufficiently.

Soil microbes have a profound influence on physiological, molecular, and biochemical processes in plants as well as plant communities. Rhizobium spp., plantgrowth-promoting rhizobacteria (PGPR), and arbuscular mycorrhizal fungi increase crop yields, whereas harmful pathogens damage crops and lower yields. It is estimated that $1 \mathrm{~g}$ of soil contains as many as $1,000,000$ bacteria and fungi from thousands of different species (32), and less than $1 \%$ of these microbes can be cultured in the laboratory; therefore, cultureindependent methods should provide a more comprehensive assessment of the microbial community in the soil. There have been several reports comparing soil microbial diversity in organic and conventional farms but the results are contradictory; showing either higher microbial diversity in organic farms $(20,22,23)$ or similar levels of diversity in both types of farms $(10,33)$. One of the major reasons for this controversy may be due to methodological differences (e.g., biolog versus terminal restriction fragment length polymorphism) or difficulties in the assessment of the entire microbial community.

Pyrosequencing is a DNA-sequencing technique based on sequencing-bysynthesis (27), and has the potential to detect low numbers of both culturable and unculturable microbes $(1,26)$. In this study, we applied high-throughput 454 pyrosequencing to obtain a more comprehensive assessment of microbial communities in organic and conventional potato farms. The microbial communities of three organic and three conventional potato farms in San Luis Valley, CO were analyzed. In order to validate the results of 454 pyrosequencing, we also performed quantitative real-time polymerase chain reaction (PCR) for three known potato pathogens.

\section{MATERIALS AND METHODS}

Soil sampling and DNA extraction. Soil ( 7.5 to $15 \mathrm{~cm}$ in depth) was collected from 12 random locations from a single center pivot potato field (approximately 125 acres) at six farms with sandy loam soils in the San Luis Valley, CO (Table 1) on 25 November 2008, after harvest. Hooper, Alamosa, and Mosca farms are maintained organically, whereas Center, Monte Vista I, and Monte Vista II farms are conventional farms. To characterize the soil microbial community, DNA was extracted from a single $0.5^{-} \mathrm{g}$ sample drawn from each of the 12 locations per farm using a Ultraclean-htp 96-well soil DNA kit (MoBio, Carlsbad, CA) according to the manufacturer's instructions, except for the addition of an extra ethanol wash and an additional purification step using AMPure Beads (Agencourt). The DNA was quantified using a Nanodrop spectrophotometer (Nanodrop Technologies, Wilmington, DE); all DNA had an absorbance at 260:280 $\mathrm{nm}$ ratio between 1.7 and 1.9 and was amplified by PCR as described in the following section. All 12 PCR reactions per farm were combined to form a single ribosomal (r)RNA library from each farm for pyrosequencing.

Pyrosequencing analyses. Amplification of the internal transcribed spacer 1 of the rRNA gene complex was performed with primers listed in Table 2. The lowercase of the above primers are necessary 
adapters for binding and amplification using the pyrosequencing process, underlined sequences are unique barcodes applied to each soil sample, and the uppercase regions are primers targeted to conserved regions of the $18 \mathrm{~S}$ and $5.8 \mathrm{~S}$ rRNA genes. The primers listed in Table 2 have been previously employed in several studies $(4,17,24,30)$ and have clearly demonstrated an ability to amplify a wide diversity of fungi belonging to the phyla Ascomycota, Basidiomycota, Zygomycota, Oomycota, Chytridiomycota, and Plasmodiophoromycota, as well as other eukaryotes, but not bacterial or plant DNA (24). PCR reactions contained $20 \mathrm{ng}$ of soil DNA, $10 \mu \mathrm{l}$ of $2 \times$ jumpstart reaction mix (Sigma-Aldrich, St. Louis), $3 \mathrm{mM} \mathrm{MgCl}_{2}$, $10 \mu \mathrm{M}$ fluorescein, and $200 \mathrm{nM}$ forward and reverse primers and were brought to $20 \mu \mathrm{l}$ with $\mathrm{dH}_{2} \mathrm{O}$. The PCR reactions were performed for 30 cycles at $95^{\circ} \mathrm{C}$ for $30 \mathrm{~s}$, $55^{\circ} \mathrm{C}$ for $30 \mathrm{~s}$, and $72^{\circ} \mathrm{C}$ for $60 \mathrm{~s}$. Following PCR, the products were visually checked on an agarose gel, and each successful reaction was purified using AMPure beads. Pyrosequencing was performed under contract with the University of Florida Genomics Facility.

Pyrosequencing error rates are estimated to be approximately 5 errors/kb (9). In order to minimize the effects of sequencing errors $(16,31)$, all reads that contained ambiguous nucleotides, a single nucleotide mismatch with the PCR primer, or were of atypical length $(<175$ or $>225 \mathrm{bp})$ were removed from the dataset using Mothur version 1.7 (29). All sequence reads were also trimmed to a common length of 175 bp to reduce computational complexity and the effect of various sequence lengths on operational taxonomic unit (OTU) assignment. From this trimmed, high-quality dataset, 2,000 sequence reads from each site-specific library were randomly selected and aligned using MUSCLE (parameters set to -maxiters 2) (8). Using Mothur version 1.7, pairwise genetic dis- tances between sequences were calculated ( calc $=$ onegap, countends $=\mathrm{F})$, sequences were clustered into OTUs, and Chaol and ACE estimates of the total OTU richness were calculated $(5,6)$. For each site, all reported OTU abundances are relative abundances determined by dividing the number of reads for any given OTU by the total number of reads obtained for that site. Taxonomic assignment was performed by comparison of a representative sequence from each OTU to the GenBank nucleotide database downloaded on 19 November 2009. The nearest neighbor present in GenBank and its homology $(H)$ to the representative sequence are reported. $H$ was calculated using the equation $H=[(I-$ $G) / L] \times 100$, where $L=$ length of query sequence, $I=$ identities (total number of correct bases), and $G=$ gaps (total number of all missing bases). Alternatively, sequences were assigned to the lowest common taxonomic unit using MEGAN ( minimum support $=1$, minimum blast

Table 1. Site descriptions of the three organic and three conventional farms in the San Luis Valley, CO

\begin{tabular}{|c|c|c|c|c|c|c|}
\hline Farm code & Location & Management & Rotation crop & Potato cultivar & Pesticides $^{\text {a }}$ & Compost, fertilizer ${ }^{b}$ \\
\hline Org-I & Hooper & Organic & Rye, pea, alfalfa, grass & Canela Russet & $\ldots$ & Green manure straw \\
\hline Org-II & Alamosa & Organic & Rye & Sangre & $\ldots$ & Green manure straw \\
\hline Org-III & Mosca & Organic & Sudangrass & $\begin{array}{l}\text { Smooth skins, } \\
\text { fingerlings }\end{array}$ & $\ldots$ & Green manure straw \\
\hline Con-I & Center & Conventional & Sorghum, sudangrass & $\begin{array}{l}\text { Russets, } \\
\text { specialty cultivars }\end{array}$ & $\begin{array}{l}\text { Dual, Headline, } \\
\text { Endigo ZC, Bravo, } \\
\text { Fulfill, Super Tin } \\
\text { 80WP }\end{array}$ & $\begin{array}{l}\text { Preplanting: } 80 \text { units (80:60:40 NPK); } \\
\text { zinc, } 2.5 \text { units; sulfur, } 25 \text { units. } \\
\text { During the season: } 40 \text { units } \\
\text { (liquid band) (NPK) }\end{array}$ \\
\hline Con-II & Monte Vista I & Conventional & Barley & $\begin{array}{l}\text { Russet } \\
\text { Norkotah Line } 3\end{array}$ & $\begin{array}{l}\text { Dual, Headline, } \\
\text { Endigo ZC, Bravo, } \\
\text { Fulfill, Super Tin } \\
\text { 80WP }\end{array}$ & $\begin{array}{l}\text { Preplanting: } 70 \text { units N (dry broadcast, 5; } \\
\text { liquid band, 65), } 229 \text { units P (dry } \\
\text { broadcast, 20; liquid band, 209), } \\
50 \text { units K (dry broadcast); zinc, } 3 \text { units; } \\
\text { sulfur, } 14.5 \text { units. During the season: } \\
60 \text { units N (liquid band) }\end{array}$ \\
\hline Con-III & Monte Vista II & Conventional & Green manure barley & Canela Russet & $\begin{array}{l}\text { Vydate, in-furrow } \\
\text { Leverage }\end{array}$ & $\begin{array}{l}\text { Preplanting: } 70 \text { units (80:60:40 NPK) } \\
\text { broadcast in the field. During the season: } \\
80 \text { units (liquid band) }\end{array}$ \\
\hline
\end{tabular}

${ }^{a}$ Pesticides were applied three times in 2008 for conventional farms.

${ }^{\mathrm{b}}$ Green manure straw was plowed under.

Table 2. Primers and probes used for 454 pyrosequencing and quantitative real-time polymerase chain reaction (PCR)

\begin{tabular}{|c|c|c|}
\hline Primers, probes & Sequence $\left(5^{\prime} \text { to } 3^{\prime}\right)^{\text {a }}$ & Reference \\
\hline 454 Pyrosequencing & & $4,17,24,30$ \\
\hline $2234 \mathrm{C}$ Org I & gectccetcgegccatcagAAGCAACGCA GTTTCCGTAGGTGAACCTGC & $\ldots$ \\
\hline 2234C OrgII & gectcectcgegccatcagAACGTACCCA GTTTCCGTAGGTGAACCTGC & $\ldots$ \\
\hline 2234C OrgIII & gcetccetcgcgccatcagAACGTAGGCA GTTTCCGTAGGTGAACCTGC & $\ldots$ \\
\hline 2234C ConI & gectccetcgegccatcagAACGTTGCCA GTTTCCGTAGGTGAACCTGC & $\ldots$ \\
\hline 2234C ConII & gectccetcgegccatcagAACGTTCGCA GTTTCCGTAGGTGAACCTGC & $\ldots$ \\
\hline 2234C ConIII & gectcectegcgccatcagAACGATGGCA GTTTCCGTAGGTGAACCTGC & $\ldots$ \\
\hline $3126 \mathrm{~T}$ & gecttgccagcecgctcagATATGCTTAAGTTCAGCGGGT & $\ldots$ \\
\hline \multicolumn{3}{|l|}{ Real-time PCR } \\
\hline Alternaria solani & & 28 \\
\hline Forward primer & GTATGTTCTTCCTTATGGGCAAATG & $\ldots$ \\
\hline Reverse primer & СTCTACTTTGTTTATGTTATTTAACCAAGAATG & $\ldots$ \\
\hline Pythium ultimum & & 7 \\
\hline Forward primer & TGTTTTCATTTTTGGACACTGGA & $\ldots$ \\
\hline Reverse primer & TCCATCATAACTTGCATTACAACAGA & $\ldots$ \\
\hline TaqMan probe & CGGGAGTCAGCAGGACGAAGGTTG & $\ldots$ \\
\hline Phoma foveata & & 7 \\
\hline Forward primer & GCGTCATTTGTACCTTCAAGCTC & $\ldots$ \\
\hline Reverse primer & TTTAAGGCGAGTCTACACGCAA & $\ldots$ \\
\hline TaqMan probe & CTTGGTGTTGGGTGTTTGTCTCGCC & $\ldots$ \\
\hline
\end{tabular}

${ }^{a}$ Lowercase letters indicate necessary adapters for binding and amplification using the pyrosequencing process; underlined sequences are unique barcodes applied to each soil sample. 
score $=250$, top percentage $=0$, win score $=0)(13)$.

Quantitative real-time PCR analysis. Quantitative real-time PCR was performed using TaqMan Universal PCR master mix (Applied Biosystems, Foster City, CA) for Pythium ultimum and Phoma foveata and SYBR Green JumpStart Taq Ready Mix (Sigma-Aldrich) for Alternaria solani. Primers and probes used in this study are listed in Table 2. PCR reactions were performed with 10 replicates per farm using rosequencing. Reaction mixtures for $P y$ thium ultimum and Phoma foveata consisted of $10 \mu \mathrm{l}$ of TaqMan Universal PCR master mix, $300 \mathrm{nM}$ primers, $100 \mathrm{nM}$ probe which contained the reporter dye FAM (6-carboxy-fluorescein) at the $5^{\prime}$ end and the quencher TAMPA (6-carboxytetramethylrhodamine) at the $3^{\prime}$ end, and 2 $\mu \mathrm{l}$ of DNA in a total volume of $20 \mu \mathrm{l}$. PCR reactions were performed in a Bio-Rad iCycler with the following condition: $95^{\circ} \mathrm{C}$ for $15 \mathrm{~min}$ and 40 cycles of $95^{\circ} \mathrm{C}$ for $15 \mathrm{~s}$ and $60^{\circ} \mathrm{C}$ for $1 \mathrm{~min}$. Reaction mixtures for A. solani consisted of $10 \mu \mathrm{l}$ of SYBR Green JumpStart Taq Ready Mix, $10 \mathrm{nM}$ fluorescein, $3 \mathrm{mM} \mathrm{MgCl}$, and $300 \mathrm{nM}$ primers. PCR reaction was performed in a Bio-Rad iCycler with the following condition: $95^{\circ} \mathrm{C}$ for $15 \mathrm{~min}$ followed by $40 \mathrm{cy}$ cles of $95^{\circ} \mathrm{C}$ for $15 \mathrm{~s}, 60^{\circ} \mathrm{C}$ for $30 \mathrm{~s}$, and $72^{\circ} \mathrm{C}$ for $30 \mathrm{~s}$. Regular PCR was performed with the same primer sets, soil DNA, and Ex-Taq DNA polymerase (Takara Bio). PCR amplicons were ligated into the TOPO-TA cloning vectors (Invitrogen) and sequenced with BigDye Sequencing (Applied Biosystems). Standard curves were obtained using 10 -fold serial dilutions $\left(10^{-7}\right.$ to $\left.10 \mathrm{ng}\right)$ of these plasmids.

Nutrient analysis. Soils collected from each farm were dried and sent to the soil testing laboratory at Colorado State University for analysis of soil $\mathrm{pH}$, electric conductivity, organic matter, and other mineral nutrients.

Statistical analysis. All reported values are arithmetic means and standard deviations. A two-tailed $t$ test was used to comthe same DNA extracts used for 454 py- pare organic and conventional farms. The degree of similarity between samples was determined using Jaccard's similarity index based on either presence or absence data $\left(J_{\text {class }}\right)$ or relative abundances $\left(J_{\text {abund }}\right)$, where $J_{\text {class }}$ is a measure of community membership and $J_{\text {abund }}$ is a measure of community structure. Hierarchical clustering of the cultivar-specific communities was performed by the unweighted pair group method with arithmetic mean (UPGMA) using the Jaccard similarity indices. Statistical differences in the cultivarspecific communities were determined using UniFrac (19). UniFrac distances are based on the fraction of branch lengths within a phylogenetic tree that are shared between two communities. Two forms of the UniFrac distance were employed: unweighted, which utilizes only the presence or absence of lineages (community membership); and weighted, which also considers the abundance of each lineage (community structure). The phylogenetic trees required for UniFrac were generated with Clearcut version 1.0.9, which creates a relaxed neighbor-joining tree (11).

\section{RESULTS}

Farm descriptions. Soil samples were collected from six different potato farms in the San Luis Valley of Colorado. Information about farm management, rotation of

A

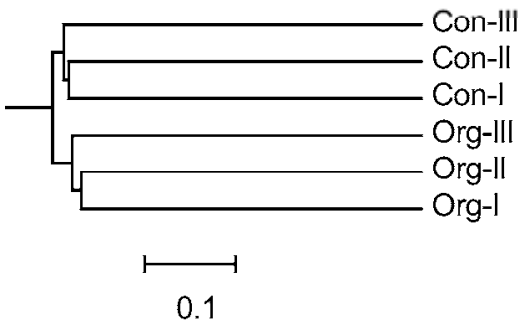

Fig. 1. Hierarchical clustering of farm-specific communities using the unweighted pair group method with arithmetic mean and Jaccard similarity indices at the $3 \%$ genetic distance level. A, Presence or absence data $\left(J_{\text {class }}\right)$ and $\mathbf{B}$, relative abundances $\left(J_{\text {abund }}\right)$.

crops, potato cultivars, and pesticides used in these farms are listed in Table 1. Soil analyses showed that organic farms in the San Luis Valley contained more carbon $(P=$ $0.064)$, nitrogen $(P=0.032)$, and potassium $(P=0.004)$ than conventional ones; whereas, no significant differences $(P>$ $0.10)$ in $\mathrm{pH}$, electrical conductivity, or other mineral nutrients were observed between organic and conventional farms (Table 3).

Microbial community membership and structure. Pyrosequencing was performed using a Roche 454 FLX sequencer and, in total, 2,000 high-quality reads per site were obtained. Multivariate analysis using relative abundance of OTUs was performed to analyze the difference in microbial communities between organic and conventional farms. The soil microbial communities differed significantly between farms, based on both community membership (unweighted Unifrac) and community structure (weighted UniFrac). Hierarchical (UPGMA) clustering of the farm-specific communities was generated using both the $J_{\text {class }}$ and $J_{\text {abund }}$ similarity indices. For the community membership measure, $J_{\text {class }}$, each farm harbored a significantly different community based on the unweighted UniFrac procedure $(P<$ 0.001 ; data not shown), although conventional and organic farms were separated into two groups (Fig. 1A). The community

B

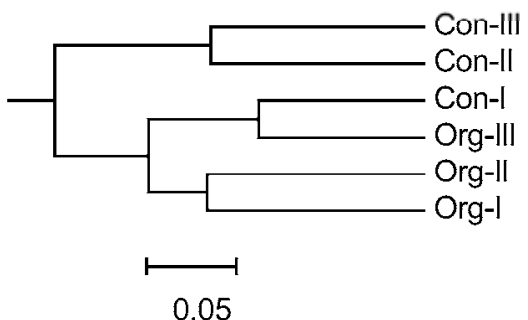

Table 3. Soil nutrient analysis for the three organic and three conventional farms in the San Luis Valley, CO

\begin{tabular}{|c|c|c|c|c|c|c|c|}
\hline \multirow[b]{2}{*}{ Parameter } & \multicolumn{3}{|c|}{ Organic } & \multicolumn{3}{|c|}{ Conventional } & \multirow[b]{2}{*}{$P$ value $^{\text {a }}$} \\
\hline & I & II & III & I & II & III & \\
\hline $\mathrm{pH}$ & 7.6 & 7.6 & 7.4 & 7.4 & 7.5 & 6.3 & 0.298 \\
\hline $\mathrm{EC}(\mathrm{mS})^{\mathrm{b}}$ & 0.9 & 2.0 & 2.6 & 0.5 & 1.8 & 0.8 & 0.276 \\
\hline $\mathrm{C}(\%)$ & 0.99 & 1.02 & 0.71 & 0.73 & 0.52 & 0.58 & 0.064 \\
\hline $\mathrm{N}(\%)$ & 0.101 & 0.099 & 0.084 & 0.077 & 0.045 & 0.058 & 0.032 \\
\hline $\mathrm{C}: \mathrm{N}$ & 9.82 & 10.32 & 9.58 & 9.55 & 12.02 & 10.21 & 0.423 \\
\hline $\mathrm{NO}_{3}-\mathrm{N}$ & 26.4 & 33.6 & 112.7 & 11.9 & 57.1 & 10.5 & 0.381 \\
\hline $\mathrm{P}(\mathrm{ppm})$ & 39.7 & 26.0 & 26.8 & 14.7 & 26.4 & 23.7 & 0.179 \\
\hline $\mathrm{K}(\mathrm{ppm})$ & 585 & 552 & 595 & 229 & 367 & 200 & 0.004 \\
\hline $\mathrm{Zn}(\mathrm{ppm})$ & 3.5 & 2.0 & 3.2 & 2.9 & 1.5 & 3.0 & 0.551 \\
\hline $\mathrm{Fe}(\mathrm{ppm})$ & 9.1 & 4.0 & 4.1 & 7.4 & 4.6 & 10.2 & 0.515 \\
\hline $\mathrm{Mn}(\mathrm{ppm})$ & 2.1 & 2.0 & 6.8 & 1.8 & 2.1 & 10.7 & 0.729 \\
\hline $\mathrm{Cu}(\mathrm{ppm})$ & 1.5 & 2.5 & 3.7 & 1.3 & 1.6 & 1.8 & 0.200 \\
\hline
\end{tabular}

${ }^{a} P$ value determined using a two-tailed $t$ test.

${ }^{\mathrm{b}} \mathrm{EC}=$ electrical conductivity. 
structure, $J_{\text {abund }}$, was also unique to each farm based on the weighted UniFrac procedure $(P<0.001$; data not shown $)$. In this case, three groups were apparent (i.e., ConII-ConIII, ConI-OrgIII, and OrgIOrgII; Fig. 1B). These results indicate that community membership is clustered depending on the farm management (organic versus conventional) whereas community structure is more variable.

Pyrosequencing analysis of microbial diversity in organic and conventional potato farms. Genetic distance from 0 to $10 \%$ was used to examine soil communities from species level (lower genetic distance) to phyla level (higher genetic distance). Neither the observed OTUs $\left(\mathrm{S}_{\mathrm{obs}}\right)$ nor Chaol estimates $\left(S_{\text {Chao }}\right)$ of the total number of OTUs in each soil sample differed significantly between organic and conventional farms (Fig. 2A and B), with an average $S_{\text {obs }}$ of 581 and an $S_{\text {Chao }}$ of 1,674 OTUs across all sites (3\% genetic distance). The genetic distance of $3 \%$ was
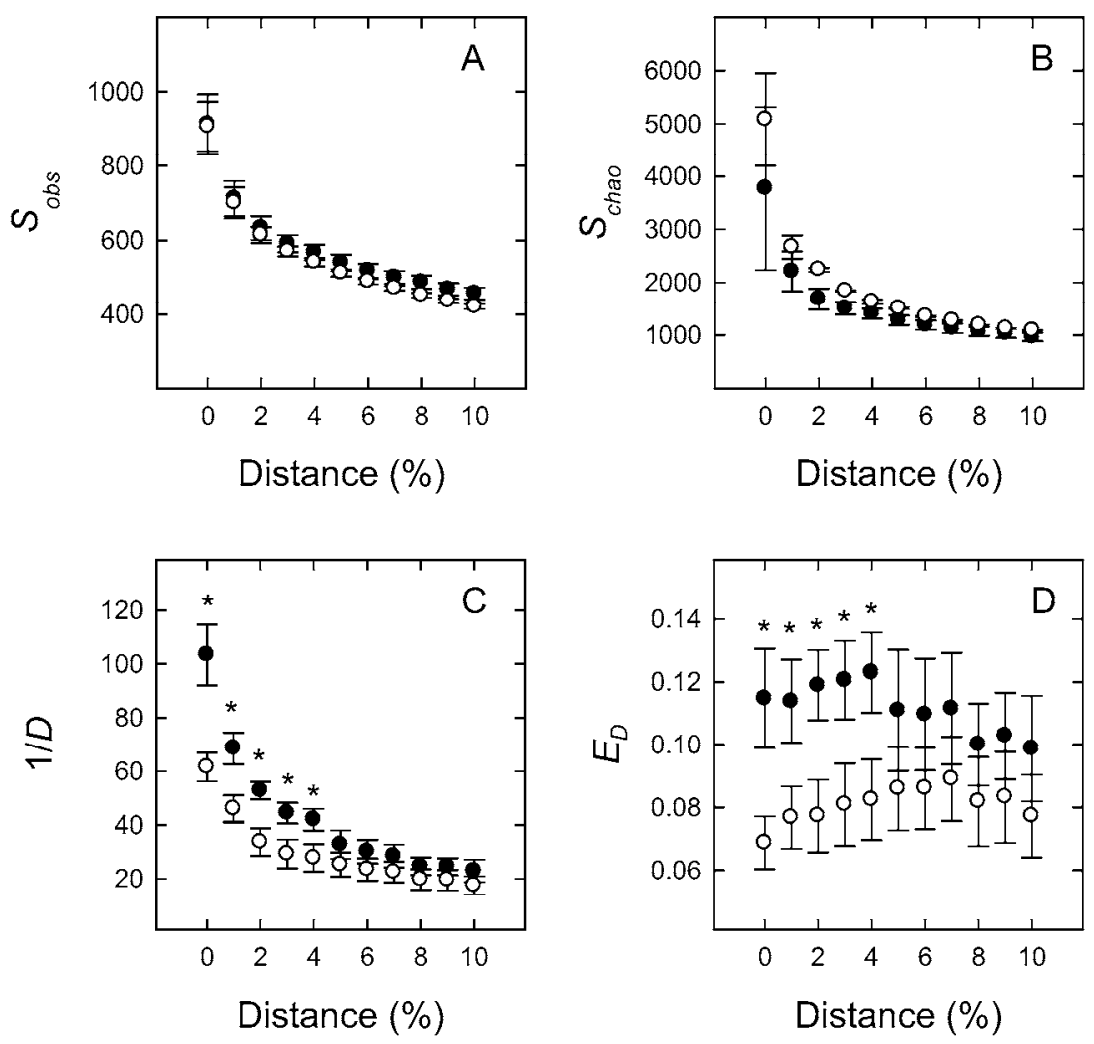

Fig. 2. Soil microbial community characteristics in three organic and three conventional farms in the San Luis Valley, CO. A, Number of observed operational taxonomic units (OTUs) $\left(S_{o b s}\right)$ for conventional farms (open circles) and organic farms (dark circles). B, Estimated OTUs by Chao1 $\left(S_{\text {chao }}\right)$ for conventional farms (open circles) and organic farms (dark circles). C, Simpson's Reciprocal Index $(1 / D)$ for conventional farms (open circles) and organic farms (dark circles). D, Simpson's Evenness $\left(E_{D}\right)$ for conventional farms (open circles) and organic farms (dark circles). Values were calculated at genetic distances from 0 to $10 \%$, and values shown are means \pm standard deviation of triplicates; * denotes significant difference using a two-tailed $t$ test $(P<0.05)$.

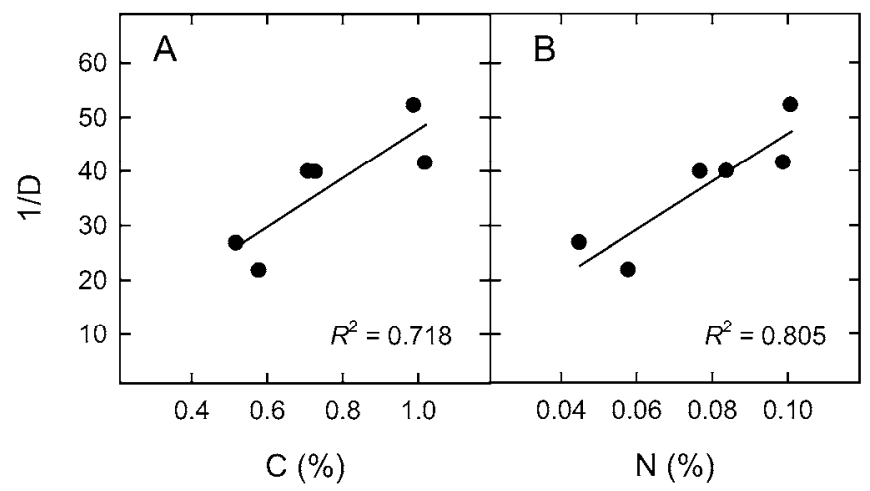

Fig. 3. Relationship between soil microbial diversity (Simpson's Reciprocal Index $[1 / D]$ ) and soil nutrients across three organic and three conventional farms in the San Luis Valley, CO. A, Carbon (\%) and $\mathbf{B}$, nitrogen (\%). $1 / D$ was determined at a genetic distance of $3 \%$ and each point is a different farm. chosen for further analysis (i) to provide the highest level of taxonomic information, (ii) because it was significantly different between farms, and (iii) to avoid possible pyrosequencing error.

Microbial diversity was calculated with Simpson's Reciprocal Index (1/D) and showed significantly higher microbial diversity levels in the organic farms compared with the conventional farms when OTUs were defined at genetic distances $\leq 4 \%$ (Fig. 2C). Similarly, Simpson's Evenness $\left(\mathrm{E}_{\mathrm{D}}\right)$ showed a higher community evenness in organic farms at genetic distances $\leq 4 \%$ (Fig. 2D). These results showed that organic potato farms in the San Luis Valley have significantly higher microbial diversity and evenness than conventional potato farms. A positive correlation was found between microbial diversity and both soil carbon $(r=0.847)$ and nitrogen $(r=0.897)$ content (Fig. 3), implying that these two macro nutrients may be important to support the microbial diversity in potato farms in San Luis Valley.

Taxonomic analysis of pyrosequencing data. Taxonomic assignment of the OTUs and their relative abundances were determined using MEGAN (version 3.7). Primers used in this study amplified algae and species of Cercozoa, Ciliophora, Heterolobosea, Nematoda, and Dinophyceae in addition to fungi. At the phyla level, conventional farms contained more members of Ascomycota $(P=0.079)$ and Streptophyta $(P=0.025)$ than organic farms (Table 4). Species of Blastocladiomycota and Dinophyceae were found only in organic farms, whereas the class Chrysophyceae was found only in conventional farms (Table 4). In Table 4, 37.9 to $76.7 \%$ of the OTUs were unassigned to a phyla, due to the following reasons: (i) we used a minimum blast score of 250 to reduce the false positives, (ii) the top 10 blast hits in GenBank did not contain any taxonomic information (i.e. uncultured or unassigned), (iii) a homologous sequence was not present in the database of GenBank, or (iv) an OTU matched two or more phyla.

Alternatively, all sequences were first assigned to OTUs (3\% genetic distance level) and the relative abundances between organic and conventional farms were tested using a two-tailed $t$ test; only those OTUs with significant difference $(P<0.05)$ are listed in Table 5. A tentative taxonomic assignment of these OTUs was determined by blasting a representative sequence from each OTU. The Alternaria spp. OTU, which contains both $A$. solani, the casual agent of early blight disease, and A. alternata, the casual agent of brown spot, was detected in all organic and conventional farms; however, its relative abundance was significantly lower in organic farms compared with conventional farms (Table 5). It should be noted that there are three different OTUs in Table 5 designated "Alternaria spp.", which means that, although 
each OTU differed from each other by $3 \%$, their nearest neighbors contained within the GenBank database were similar. Therefore, it is likely that they represent different species or strains of Alternaria but they cannot be differentiated with the 175-bp DNA sequence obtained from pyrosequencing. Ulocladium spp. are the causal agents of Ulocladium blight and their relative abundance was also higher in conventional farms (Table 5). In contrast, Pythium ultimum, which causes Pythium leak or water rot, was found in all three organic and one conventional farms, and its relative abundance was higher in organic farms (Table 5). Other potato pathogens such as Phoma foveata, Rhizoctonia solani, Spongospora subterranea, and Pythium spp. were also detected but did not differ significantly between the organic and conventional farms $(P>0.05)$. Phytophthora infestans, $P$. erythroseptica, and Fusarium spp. are common pathogens worldwide; however, they were not present at detectable levels in any of the farms included in this study.

Quantitative real-time PCR for potato pathogens. In order to validate the results of 454 pyrosequencing, the abundance of some potato pathogens was measured quantitatively using real-time PCR. A. solani, Pythium ultimum, and Phoma foveata were selected because they represented pathogens that were (i) more abundant in conventional farms, (ii) more abundant in organic farms, or (iii) showed no significant difference between organic and conventional farms, respectively. Primers and probes for TaqMan real-time PCR were designed according to the literature $(7,28)$.
The TaqMan probe reported in the literature for A. solani (28) did not work in our hands; therefore, we used the SYBR green method for detecting A. solani.

A. solani was shown to be present in all six farms (Fig. 4A) but its abundance was significantly higher (approximately threefold) in the conventional farms. Pythium ultimum was also detected in all six farms (Fig. 4B), although it was not detectable in two conventional farms according to the 454 pyrosequencing data, and was significantly higher in organic farms by approximately fourfold. Phoma foveata was also detected in all six farms with real-time PCR (Fig. 4C) and, like the 454 pyrosequencing data, did not significantly differ between organic and conventional farms. Quantitative PCR was more sensitive at detecting the presence of A. solani, Py-

Table 4. Relative abundance (\%) of soil microbial Phyla at three organic and three conventional farms in the San Luis Valley, CO determined using MEGAN

\begin{tabular}{|c|c|c|c|c|c|c|c|}
\hline \multirow[b]{2}{*}{ Phyla $^{a}$} & \multicolumn{3}{|c|}{ Organic } & \multicolumn{3}{|c|}{ Conventional } & \multirow[b]{2}{*}{$P$ value $^{b}$} \\
\hline & $\mathbf{I}$ & II & III & $\mathbf{I}$ & II & III & \\
\hline Ascomycota & 31.3 & 17.75 & 39.2 & 46.5 & 43.65 & 42.85 & 0.079 \\
\hline Basidiomycota & 2.75 & 1.55 & 2.1 & 2.8 & 2.25 & 2.5 & 0.372 \\
\hline Cercozoa & 0.1 & 0 & 0 & 0 & 0 & 12.95 & 0.377 \\
\hline Ciliophora & 0.65 & 2.5 & 3.1 & 1.8 & 1.05 & 1.85 & 0.545 \\
\hline Fungi incertae sedis & 1.6 & 0.85 & 0.55 & 0.4 & 1.65 & 0.8 & 0.923 \\
\hline Streptophyta & 0.35 & 0.15 & 0 & 0.55 & 1 & 0.7 & 0.025 \\
\hline Chytridiomycota & 0.75 & 0.15 & 0.1 & 0.25 & 0.95 & 0.3 & 0.616 \\
\hline Oomycetes & 0.1 & 0.1 & 0 & 0.4 & 0.15 & 0.05 & 0.289 \\
\hline Heterolobosea & 0.3 & 0 & 0 & 0 & 0 & 0.1 & 0.561 \\
\hline Nematoda & 0 & 0.1 & 0 & 0 & 0.1 & 0 & 1.000 \\
\hline Glomeromycota & 0 & 0.05 & 0 & 0 & 0.1 & 0 & 0.678 \\
\hline Blastocladiomycota & 0 & 0 & 0.15 & 0 & 0 & 0 & 0.374 \\
\hline Chrysophyceae & 0 & 0 & 0 & 0.1 & 0 & 0 & 0.374 \\
\hline Dinophyceae & 0 & 0.1 & 0 & 0 & 0 & 0 & 0.374 \\
\hline Unassigned $^{c}$ & 62.1 & 76.7 & 54.8 & 47.2 & 49.1 & 37.9 & 0.054 \\
\hline
\end{tabular}

a Sequences for internal transcribed spacer 1 of the rRNA gene and GenBank nucleotide database downloaded on 19 November 2009 were used in MEGAN version 3.7 (minimum blast score $=250$ ). In cases where a phylum does not exist in the current National Center for Biotechnology Information taxonomic tree, taxa listed are as follows. No rank: Fungi incertae sedis, Cercozoa, Ciliophora, Oomycetes; Class: Heterolobosea, Chrysophyceae, and Dinophyceae.

${ }^{\mathrm{b}} P$ value determined using a two-tailed $t$ test.

${ }^{c}$ Unassigned includes sequences that either match two or more phyla or no matching neighbors in GenBank (blast score $>250$ ).

Table 5. Relative abundance (\%) of significantly different soil microbial operational taxonomic units (OTUs; $3 \%$ genetic distance) at three organic and three conventional farms in the San Luis Valley, CO determined using Blast

\begin{tabular}{|c|c|c|c|c|c|c|c|c|c|}
\hline \multirow[b]{2}{*}{ Rank } & \multicolumn{2}{|l|}{ OTU $^{\mathbf{a}}$} & \multicolumn{3}{|c|}{ Organic } & \multicolumn{3}{|c|}{ Conventional } & \multirow[b]{2}{*}{$P^{\mathbf{b}}$} \\
\hline & Taxa ID, nearest neighbors & $\boldsymbol{H}$ & $\mathbf{I}$ & II & III & $\mathbf{I}$ & II & III & \\
\hline 2 & Alternaria spp. (AB247177, AM237288, AY372685, AY154716) & 100 & 4.55 & 2.85 & 0.1 & 6.15 & 9.5 & 12.55 & 0.038 \\
\hline 50 & Uncultured fungus (GQ508267.1) & 100 & 0.25 & 0.1 & 0 & 0.5 & 0.9 & 0.6 & 0.017 \\
\hline 66 & Uncultured fungus (FJ554355.1) & 87.4 & 0.45 & 0.4 & 0.8 & 0.1 & 0.05 & 0 & 0.018 \\
\hline 70 & Alternaria spp. (AB247177, AM237288, AY372685, AY154716) & 98.9 & 0.1 & 0.15 & 0 & 0.35 & 0.3 & 0.7 & 0.050 \\
\hline 77 & Epicoccum sp. FJ210555.1 & 97.7 & 0 & 0 & 0.15 & 0.65 & 0.2 & 0.5 & 0.047 \\
\hline 78 & Uncultured Ciliophora (FJ553222) & 87.4 & 0.05 & 0.05 & 0.05 & 0.4 & 0.5 & 0.4 & 0.000 \\
\hline 125 & Uncultured Ciliophora (FJ553222) & 92.0 & 0.15 & 0.2 & 0.25 & 0.05 & 0.1 & 0.05 & 0.016 \\
\hline 146 & Alternaria spp. (AB247177, AM237288, AY372685, AY154716) & 97.7 & 0.05 & 0 & 0 & 0.2 & 0.1 & 0.3 & 0.038 \\
\hline 171 & Mortierella hyalina (AJ878777) & 98.9 & 0 & 0 & 0 & 0.05 & 0.1 & 0.1 & 0.007 \\
\hline 212 & Unassigned & 66.9 & 0 & 0 & 0 & 0.15 & 0.05 & 0.2 & 0.039 \\
\hline 225 & Unassigned & 21.2 & 0.15 & 0.05 & 0.2 & 0 & 0 & 0 & 0.039 \\
\hline 271 & Ulocladium spp. (GQ169445) & 89.7 & 0 & 0 & 0.05 & 0.1 & 0.1 & 0.1 & 0.007 \\
\hline 275 & Pythium ultimum (AF452158) & 76.6 & 0.05 & 0.1 & 0.1 & 0.05 & 0 & 0 & 0.047 \\
\hline 276 & Uncultured Ascomycota (FN562050.1) & 97.7 & 0.15 & 0.05 & 0.1 & 0 & 0 & 0 & 0.026 \\
\hline 387 & Uncultured fungus (FJ779209.1) & 84.0 & 0.05 & 0.05 & 0.1 & 0 & 0 & 0 & 0.016 \\
\hline 399 & Uncultured Ciliophora (FJ554262.1) & 90.3 & 0.1 & 0.05 & 0.05 & 0 & 0 & 0 & 0.016 \\
\hline
\end{tabular}

${ }^{a}$ Representative sequences for internal transcribed spacer 1 of the ribosomal RNA gene from each OTU were blasted against GenBank nucleotide database downloaded on 19 November 2009. Rank of the listed OTU is based on the average relative abundance across all six sites based on a total of 1,549 OTUs detected at the $3 \%$ genetic distance level using Mothur. Taxa ID is the lowest common taxa of the top hits in GenBank (accession numbers of equivalent homologs are in parentheses). OTUs were considered to be unassigned if homology or $H \leq 75 \%$.

b $P$ value determined using a two-tailed $t$ test. 
thium ultimum, and Phoma foveata in the soil (i.e., present at all six farms). However, a strong correlation was observed between real-time PCR data and 454 pyrosequencing results for $A$. solani, Pythium ultimum, and Phoma foveata ( $r=0.982$, 0.923 , and 0.856 , respectively). For $A$. solani, the most abundant Alternaria $\mathrm{sp}$. OTU (rank $=2$, see Table 5) was used.

\section{DISCUSSION}

In this study, the soil microbial community was assessed with 454 pyrosequencing in six potato farms to obtain insight on the effect of organic farming on soil microbial species. The six farms used in this study have different management and crop rotation schemes but are in the same general location and climate zone; thus, the influence of location and climate in this study should be minimal. Each soil was characterized in terms of macro- and micronutrients, electric conductivity, and $\mathrm{pH}$. It was found that organic farms in the San Luis Valley had more carbon, nitrogen, and potassium than conventional farms.

Both bacterial and fungal diversity are important indices to evaluate the condition of soils. There have been several reports comparing the bacterial and fungal diversity between organic and conventional

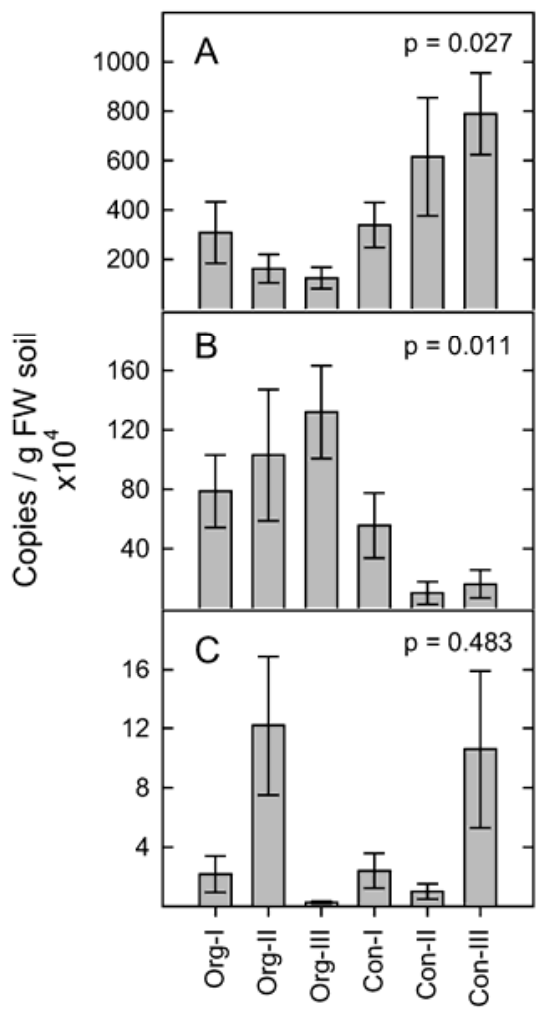

Fig. 4. Fungal abundance (i.e., gene copies) of three potato pathogens in the soil of three organic (Org) and three conventional (Con) farms in the San Luis Valley, CO. A, Alternaria solani; B, Pythium ultimum; and C, Phoma foveata. Data shown are means \pm standard deviation of 10 replicates. $P$ values were determined using a two-tailed $t$ test comparing organic and conventional farms. farms with varying results (i.e., higher diversity in organic farms $[20,22,23]$ and similar diversity in both farms $[10,33])$. In this study, we employed 454 pyrosequencing to obtain a comprehensive picture of the microbial communities associated with organic and conventional potato farms in the San Luis Valley, using primers that amplify fungi (members of Ascomycota, Basidiomycota, Zygomycota, Oomycota, Chytridiomycota, and Plasmodiophoromycota) and other eukaryotes.

Pyrosequencing revealed that both organic and conventional farms contained similar numbers of microbial OTUs. However, organic farms in San Luis Valley showed higher community diversity and evenness than conventional farms. Higher community evenness found in organic farms implies a more stable interaction between plants and soil microbial species and between microbial species (3). This could be due to the fact that organic agriculture uses composts which sustain and favor fungal growth or the fact that conventional agriculture uses pesticides, which have profound effects on soil microbial composition and alter the overall balance of microbes in the soil (2). For example, reduced pesticide use may promote a more even microbial community by not interfering with or reducing the natural microbe-microbe or plantmicrobe interactions that help to suppress the dominance of any one particular species. Long-term analyses for microbial diversity and evenness will be necessary to validate this hypothesis.

Most of the OTUs did not show significant differences in relative abundance between organic and conventional farms but there were 16 OTUs that did show significant differences. Among those OTUs, several potato pathogens were included. Alternaria spp., Ulocladium spp., and Pythium ultimum are common potato pathogens found in San Luis Valley, and their relative abundance was significantly different between organic and conventional farms (i.e., Alternaria spp. and Ulocladium spp. were more abundant in conventional farms whereas P. ultimum was more abundant in organic farms).

Both culture-dependent and cultureindependent methods have been employed to analyze the soil microbial community to date. The limitation of culture-dependent methods is that they detect approximately $1 \%$ of soil microbes, because most soil microbes cannot be cultured in vitro. Culture-independent biochemical methods such as phospholipid fatty acid or fatty acid methyl ester profiles have also been used but several limitations are inherent to these methods (e.g., more than two species can have the same profile and one species may have numerous fatty acids; 33). PCRbased methods such as denaturing gradient gel electrophoresis, terminal restriction fragment length polymorphism, and length heterogeneity PCR have also been widely used to study soil microbial communities. Although these methods can amplify both culturable and unculturable microbes in soils, their sensitivity and resolution do not match that of pyrosequencing $(15,21)$. Pyrosequencing can provide thousands of sequences from a single soil sample, increasing our ability to detect less abundant species, and the DNA sequence data provided allows for increased resolution of microbial taxa. Although the qualitative ability of 454 sequencing is theoretically sound and well documented (18), its quantitative ability has not been well validated. Therefore, we used quantitative real-time PCR to validate the data obtained from 454 pyrosequencing. A. solani, P. ultimum, and Phoma foveata were selected for quantitative analysis in using real-time PCR because (i) the primers, probes, and PCR conditions have already been established $(7,28)$ and (ii) these three species represented three different groups; that is, abundant in conventional farms (A. solani), abundant in organic farms (Pythium ultimum), and similar abundance (Phoma foveata). Our analysis confirmed that the quantitative PCR-determined abundances of these fungal species were in agreement with relative abundances determined using 454 pyrosequencing, suggesting that 454 pyrosequencing data is useful for both qualitative and quantitative analyses of soil microbes under our experimental conditions.

In this study, we showed that organic potato farms in the San Luis Valley, CO have higher microbial diversity and evenness than conventional farms. This is, to our knowledge, the first report describing the microbial community of organic and conventional farms using 454 pyrosequencing. This study was, however, conducted in a limited number of farms and in only one crop species; therefore, it cannot as yet be generalized that organic farming supports higher microbial diversity and evenness. Large numbers of farms from different crop species and climate zone should be analyzed to draw a clear conclusion regarding the differences between organic and conventional farms. The results shown here comparing 454 pyrosequencing data with quantitative real-time PCR could be very useful for further analysis of larger number of farms and changes in these microbial communities over time. We are currently analyzing the bacterial communities of these farms using 454 pyrosequencing to investigate whether bacterial communities also show higher diversity and evenness in organic farms and the relationship between biocontrol species and potato pathogens.

\section{ACKNOWLEDGMENTS}

A. Sugiyama was supported by a JSPS Postdoctoral Fellowship for Research Abroad and research in J. M. Vivanco's laboratory was supported by a grant from the National Science Foundation (MCB0950857). 


\section{LITERATURE CITED}

1. Acosta-Martíneza, V., Dowdb, S., Sunc, Y., and Allen, V. 2008. Tag-encoded pyrosequencing analysis of bacterial diversity in a single soil type as affected by management and land use. Soil Biol. Biochem. 40:2762-2770.

2. Arias, M. E., Gonzalez-Perez, J. A., GonzalezVila, F. J., and Ball, A. S. 2005. Soil health-a new challenge for microbiologists and chemists. Int. Microbiol. 8:13-21.

3. Badri, D. V., and Vivanco, J. M. 2009. Regulation and function of root exudates. Plant Cell Environ. 32:666-681.

4. Broz, A. K., Manter, D. K., and Vivanco, J. M. 2007. Soil fungal abundance and diversity: another victim of the invasive plant Centaurea maculosa. ISME J. 1:763-765.

5. Chao, A., and Lee, S. M. 1992. Estimating the number of classes via sample coverage. J. Am. Stat. Assoc. 87:210-217.

6. Chao, A., Ma, M. C., and Yang, M. C. K. 1993. Stopping rille and estimation for recapture debugging with unequal detection rates. Biometrika 80:193-201.

7. Cullen, D. W., Toth, I. K., Boonham, N., Walsh, K., Barker, I., and Lees, A. K. 2007. Development and validation of conventional and quantitative polymerase chain reaction assays for the detection of storage rot potato pathogens, Phytophthora erythroseptica, Pythium ultimum and Phoma foveata. J. Phytopathol. 155:309-315.

8. Edgar, R. C. 2004. MUSCLE: a multiple sequence alignment method with reduced time and space complexity. BMC Bioinf. 5:113

9. Eisen, J. A. 2007. Environmental shotgun sequencing: its potential and challenges for studying the hidden world of microbes. PLoS Biol. 5:e82.

10. Esperschutz, J., Gattinger, A., Mader, P., Schloter, M., and Fliessbach, A. 2007. Response of soil microbial biomass and community structures to conventional and organic farming systems under identical crop rotations. FEMS Microbiol. Ecol. 61:26-37.

11. Evans, J., Sheneman, L., and Foster, J. 2006. Relaxed neighbor joining: a fast distancebased phylogenetic tree construction method. J. Mol. Evol. 62:785-792.

12. Helga, W., and Lukas, K. E. 2009. The World of Organic Agriculture-Statistics and Emerging Trends 2009. Bonn, Germany.
13. Huson, D. H., Auch, A. F., Qi, J., and Schuster, S. C. 2007. MEGAN analysis of metagenomic data. Genome Res. 17:377-386.

14. Kaufman, D. G., and Franz, C. M. 1993. Biosphere 2000: Protecting our Global Environment. HarperCollins College Publishers, New York.

15. Kirk, J. L., Beaudette, L. A., Hart, M., Moutoglis, P., Klironomos, J. N., Lee, H., and Trevors, J. T. 2004. Methods of studying soil microbial diversity. J. Microbiol. Methods 58:169-188.

16. Kunin, V., Engelbrektson, A., Ochman, H., and Hugenholtz, P. 2010. Wrinkles in the rare bioshpere: pyrosequencing errors can lead to artificial inflation of diversity estimates. Environ. Microbiol. 12:118-23.

17. Lejon, D. P., Chaussod, R., Ranger, J., and Ranjard, L. 2005. Microbial community structure and density under different tree species in an acid forest soil (Morvan, France). Microb. Ecol. 50:614-625.

18. Liu, Z., Lozupone, C., Hamady, M., Bushman, F. D., and Knight, R. 2007. Short pyrosequencing reads suffice for accurate microbial community analysis. Nucleic Acids Res. 35:e120.

19. Lozupone, C., and Knight, R. 2005. UniFrac: a new phylogenetic method for comparing microbial communities. Appl. Environ. Microbiol. 71:8228-8235

20. Mader, P., Fliessbach, A., Dubois, D., Gunst, L., Fried, P., and Niggli, U. 2002. Soil fertility and biodiversity in organic farming. Science 296:1694-1697.

21. Manter, D. K., and Vivanco, J. M. 2007. Use of the ITS primers, ITS1F and ITS4, to characterize fungal abundance and diversity in mixedtemplate samples by qPCR and length heterogeneity analysis. J. Microbiol. Methods 71:7-14.

22. Oehl, F., Sieverding, E., Mader, P., Dubois, D., Ineichen, K., Boller, T., and Wiemken, A. 2004. Impact of long-term conventional and organic farming on the diversity of arbuscular mycorrhizal fungi. Oecologia 138:574-583.

23. Rangarajan, S., Saleena, L. M., and Nair, S. 2002. Diversity of Pseudomonas spp. isolated from rice rhizosphere populations grown along a salinity gradient. Microb. Ecol. 43:280-289.

24. Ranjard, L., Poly, F., Lata, J. C., Mougel, C., Thioulouse, J., and Nazaret, S. 2001. Characterization of bacterial and fungal soil communities by automated ribosomal intergenic spacer analysis fingerprints: biological and methodological variability. Appl. Environ. Microbiol. 67:4479-4487.

25. Reganold, J., Elliott, L., and Unger, Y. 1987. Long-term effects of organic and conventional farming on soil erosion. Nature 330:370-372

26. Roesch, L. F., Fulthorpe, R. R., Riva, A Casella, G., Hadwin, A. K., Kent, A. D. Daroub, S. H., Camargo, F. A., Farmerie, W. G., and Triplett, E. W. 2007. Pyrosequencing enumerates and contrasts soil microbial diversity. ISME J. 1:283-290.

27. Ronaghi, M., Uhlen, M., and Nyren, P. 1998. A sequencing method based on real-time pyrophosphate. Science 281:363, 365.

28. Rosenzweig, N., Olaya, G., Atallah, A. K., Cleere, S., Stanger, C., and Stevenson, W. R. 2008. Monitoring and tracking changes in sensitivity to azoxystrobin fungicide in Alternaria solani in Wisconsin. Plant Dis. 92:555-560.

29. Schloss, P. D., Westcott, S. L., Ryabin, T., Hall, J. R., Hartmann, M., Hollister, E. B. Lesniewski, R. A., Oakley, B. B., Parks, D. H., Robinson, C. J., Sahl, J. W., Stres, B., Thallinger, G. G., Van Horn, D. J., and Weber, C. F. 2009. Introducing Mothur: open source, platform-independent, community-supported software for describing and comparing microbial communities. Appl. Environ. Microbiol. 75:7537-7541.

30. Sequerra, J., Marmeisse, R., Valla, G., Normand, P., Capellano, A., and Moiroud, A. 1997. Taxonomic position and intraspecific variability of the nodule forming Penicillium nodositatum inferred from RFLP analysis of the ribosomal intergenic spacer and random amplified polymorphic DNA. Mycol. Res. 101:465-472.

31. Sogin, M. L., Morrison, H. G., Huber, J. A., Mark Welch, D., Huse, S. M., Neal, P. R., Arrieta, J. M., and Herndl, G. J. 2006. Microbial diversity in the deep sea and the underexplored "rare biosphere". Proc. Natl. Acad. Sci. U.S.A. 103:12115-12120.

32. Trevors, J. T. 2009. One gram of soil: A microbial biochemical gene library. Antonie Leeuwenhoek 97:99-106.

33. Wu, T., Chellemi, D. O., Graham, J. H., Martin, K. J., and Rosskopf, E. N. 2008. Comparison of soil bacterial communities under diverse agricultural land management and crop production practices. Microb. Ecol. 55:293-310. 